\title{
Development of Screening Inventory for Thai Muslim Spouses at Risk of Domestic Violence Behaviors in Satun Province
}

\author{
Kasetchai Laeheem ${ }^{1}$ \\ ${ }^{1}$ Faculty of Liberal Arts, Prince of Songkla University, Hatyai, Thailand \\ Correspondence: Kasetchai Laeheem, Faculty of Liberal Arts, Prince of Songkla University, Hatyai, Songkhla \\ 90110, Thailand. E-mail: Lkasetchai@yahoo.com
}

Received: April 11, $2014 \quad$ Accepted: May 5, $2014 \quad$ Online Published: June 24, 2014
$\begin{array}{ll}\text { doi:10.5539/ass.v10n14p138 } & \text { URL: http://dx.doi.org/10.5539/ass.v10n14p138 }\end{array}$

\begin{abstract}
The objective of this research was to develop a screening inventory for Thai Muslims spouses at risk of domestic violence behaviors in Satun Province. The study was conducted with the subject group of 1,140 households consisting of 2,280 people recruited through multi-stage sampling. The data were analyzed using the R program to find out the indexes of item-objective congruence, t-values, corrected item-total correlation coefficients, Cronbach's alpha coefficients, percentile rank scores, and the normalized t-scores.

The results of the study revealed that the screening inventory for Thai Muslims spouses at risk of domestic violence behaviors in Satun Province consisted of 48 question items with the indexes of item-objective congruence (IOC) between 0.80-1.00, the t-values between 3.668-18.655, the corrected item-total correlation coefficients between .308-.823, the Cronbach's alpha coefficients (reliability) of .936, the percentile rank scores in the range 23.62-99.87, and the normalized t-scores in the range T23-T80.11.
\end{abstract}

Keywords: screening inventory, domestic violence, risk behavior, Thai Muslims spouses

\section{Introduction}

Domestic violence has long been considered an important problem in Thai society and has severely affected abusers and the ones being abused and family members who perceive and witness the incidents. The present society does not pay adequate attention to the problem as people usually take domestic violence as private matters, problems of specific family members, human rights problems, and problems that other people cannot intervene. Thus, domestic violence has been a hidden problem in increasingly complicated society and has become difficult to prevent and solve (Kanjanakul, 1997; Promrak, 2007).

Domestic violence is the expression of intentional and physical use of force to abuse or threaten oneself, others, a group or groups of people, or the community. It can result or tends to result in injury or death, or danger to the mind, prevention of growth, or obstacle to some rights and deprivation of something that the individual or people deserve. This includes any behavior or action that violates personal rights of an individual physically, verbally, mentally, or sexually by forcing, threatening, hitting, kicking, limiting, and obstructing the rights either in public or personal life that results in physical or mental suffering of the individual being abused (Intarajit \& Karinchai, 1999; Triemchaisri, 2001). Domestic violence is an action that is unusually severe and causes damage, or a behavior that releases anger, fright, and apprehension to other people or things around the person without restraining or with intention to cause troubles to others by hurting them severely and may lead to death. It can also be a use of physical force to threaten or hurt others in order to control or occupy the person or property (Berkowitz, 1989; Stuart, 1981; Corsini, 1999). Domestic violence refers a husband's behavior which abuses his wife physically, mentally or sexually to show his power and to control her. It also refers to a repeated incident of a wife being abused by her husband physically, mentally or sexually to control or force her to do or not to do something he wants without consideration of her personal rights (Walker, 2001; Hampton, Gullotta, \& Ramos, 2006).

Abusing one's wife has caused a great deal of socio-economic burden to society in terms of health care expenditures, welfare provision, consultation costs for domestic abuse victims and prevention measures (Kanjanakul, 1997). Moreover, it can have long-term effects on society in that children from families with domestic violence can learn and absorb such violence through training and socialization (Hemmanad, 1990; 
Puawongpaet, 1994). Domestic violence can affect three concerning parties. Party 1 is the party being abused (women who are hurt). Women who are physically hurt by their husbands do not have only to be treated physically but also mentally as mental injuries are hidden inside and will remain there all their life. Mental injuries in most women are not completely treated or healed even though treatment can be done by realization of self-worth. Party 2 is the family. Domestic violence committed against women by men can affect family members, especially young children or teenagers who are psychologically affected and as a result, have negative attitudes towards family relationship that can further affect their quality of life value making them feel repressed, aggressive, roguish, and not interested in studying. Party 3 is society or the community. If parents are separated, divorced or not divorced, in lower class families, children may flee from home and become homeless, and cause both short and long run social problems (Promrak, 2007).

It can be seen that problem of domestic violence can affect people being abused and people around them physically and mentally. For example, in the case that the father hits the mother, the child or children may be hit and injured or witness such violence that can remain in their long-term memory and can make them misunderstand that problems can be solved with violence. Actually, all problems can be solved by using reasoning, talking and understanding. Besides this, being in the environment with violence against peers can result in violence against children's own families or pets when they grow up. It is obvious that violence can be transferred from parents to their children and grandchildren. If we allow violence to take place be it severe or non-severe, it can remain in society permanently, and this is why we must prevent violence so that it is not expanded into a vicious cycle (Klongpayabarn, 1999; Kungsakon \& Pojam, 2008).

Regarding spousal violence, many phenomena have shown that physical violence against wives has increasingly been more severe and that it has been done by abusers of all levels of economic statuses, all occupations, races, and religions. Moreover, men who abuse against women usually have committed violence during the pre-marital relation period and many of them have used violence outside their homes (Sonkin, Martin, \& Walker, 1985). In 2011, 30 wives were killed by husbands while 60 wives were killed by their husbands in 2012 which is a 50 percent increase (Friends of Women Foundation, 2013). In 2005, 36.66 percent of violence against women was committed by people close to them while the percentage of that increased to 46.12 in 2009 or an increase of 9.46 percent (Office of Women's Affairs and Family, 2011). Physical violence was committed against 34 percent of wives by their husbands while 30 percent had been severely abused sexually, and 50 percent had been severely abused physically and sexually (Archawanitkul \& Im-am, 2003).

Therefore, it is very necessary to study and develop a screening inventory for Thai Muslims spouses at risk of domestic violence behaviors in Satun Province to be a standard tool and to assist related organizations to be able to accurately screen individuals and to tackle the problem in the right individuals before the problem becomes more severe and becomes a social problem. Furthermore, the results of this research will be beneficial to policy forming for prevention and solutions to the problem of domestic violence before it becomes too severe and difficult to solve.

\section{Methods}

\subsection{Population and Subjects}

The population of the research was Thai Muslim married couples in Satun Province, and the subjects of 1,140 families consisting of 2,280 persons were selected. The subjects, 80 families consisting of 160 people were allocated to determine the power of discrimination and reliability; 960 families consisting of 1,920 people were allocated for analysis to find out the norms. The subjects were selected through survey and multi-stage sampling as follows: Stage 1: Stratified sampling consisting of three strata, namely, large-size, medium-size, and small-size districts classified according to the number of their population and the criteria of the Department of Administration, then two districts were selected from each stratum through simple random sampling totaling six districts. Stage 2: Selection of sub-districts through simple random sampling in which four sub-districts were selected totaling 24 sub-districts. Stage 3: Selection of villages through simple random sampling in which two villages were selected from each sub-district totaling 48 villages. Stage 4: The last stage of subject selection in which 20 Thai Muslim families were selected from each village; ten families with the problem of domestic violence, and ten families without such a problem were selected. The total number of the families selected was 960 consisting of 1,920 people (husbands and wives). The selection was done by local Muslim leaders who were asked by the researcher to assist. 


\subsection{Stages in the Development of the Screening Inventory}

The stages in the development of the screening inventory were as follows (Jamornmann, 1989; Tansawat, 2003):

1) Determining the scope, objectives, and content of domestic violence risk behaviors that were to be measured or screened, and characteristics of the target group with whom the screening inventory was to be used. The conditions of the problems of domestic violence risk behaviors were studied from the past, to the present and the future in order to be used as basic guidelines for determining the behaviors so that they are closest to the actual conditions.

2) Determining the construct and defining variables to be measured from theories related to domestic violence behaviors in order to make the definitions and specific characteristics clear by designating them in concrete forms that can be measured or observed.

3) Selecting the type and category of the screening inventory, and a 1-5 rating scale was selected. The target group was asked to determine the level of their spouse's behaviors during the last six months. The criterion for the score of each level is as follows.
4 means You have regularly been abused with that behavior.
(16 times or more)
3 means You have often been abused with that behavior.
(11-15 times)
2 means You have quite often been abused with that behavior.
(6-10 times)
1 means You have once in a while been abused with that behavior.
(Less than 6 times)
0 means
You have never been abused with that behavior.

4) Writing question items to correspond with the construct and definitions to be measured by dividing domestic violence into four aspects as follows. Aspect 1: Physical abuse consisting of 14 question items on being kicked, hit, pushed by foot, beaten, shoved, slapped, hit by knee, hit by elbow, thrown at, bitten, pinched and scratched, getting hair pulled or snatched, strangled, and burnt with a cigarette butt. Aspect 2: Emotional and mental abuse consisting of 14 question items on being scolded, being bawled or yelled at, talked at rudely, ridiculed, insulted, talked at sarcastically, abandoned without financial help, receiving no attention and no love, being mocked, despised, oppressed, threatened, detained, and teased about disabilities/impairments. Aspect 3: Sexual abuse consisting of 10 question items about being forced to have sex when one does not want to, being forced to have sex the way one does not like, being forced to have sex in a place that one does not think appropriate, being forced to have sex when one is not well, being molested in front of others, being lewd in public, being forced to watch pornography, being forced to wear clothes that reveal parts of one's body, being forced to have one's photos taken naked, and being injured while having sex. Aspect 4: Social abuse consisting of 10 question items about being detained, being obstructed from socializing with friends, being obstructed from contacting relatives, being censored on telephone calls, being confined to the house, being prohibited from working outside the home, being restricted in participating in social activities, being obstructed from talking with neighbors, being forced to travel only with family, being forced to resigned from work.

5) Testing the content validity was performed by five experts in behavioral science and psychology in terms of language and form of definitions, and to check whether each question item corresponds with the objectives of the screening inventory. After that the results were analyzed to find out the indexes of item-objective congruence and only items with the value from 0.5 were selected (Laeheem, 2010).

6) The power of discrimination and reliability of the screening inventory were tested by collecting data from 160 subjects and analyzed with the t-test. The $25 \%$ technique was used to divide the group into the high and low groups and the items with the statistical significance of the level .05 were selected (Piyapimonsit, 2005). The corrected item-total correlation coefficients were calculated and the items with the value of .20 or greater were selected (Piyapimonsit, 2005). The reliability of the entire screening inventory was tested by measuring the internal consistency and analyzing Cronbach's alpha coefficients which must be .70 or greater (Laeheem, 2010).

7) Creating norms for interpretation of meanings by collecting data from 1,920 subjects and calculating percentile rank scores and comparing to find out normalized t-scores according to the concept of Garrett (1965). The scores were then interpreted into two types. Type 1 is interpreting the meanings of the 5 scales according to the concept of Saiyod and Saiyod (2000), and Type 2 is interpreting the meanings of the two groups according to the concept of Laeheem and Sangkharat (2012). 


\subsection{The Data Collection}

The data were collected by the researcher and 24 data collecting team members (one team member for each sub-district). The team consisted of students with experiences in data collection who were specially trained to have the same understanding of the method of field data collection and the details of the question items in the screening inventory.

\subsection{Data Analysis}

The data were analyzed with the $\mathrm{R}$ program to find out the indexes of item-objective congruence, $\mathrm{t}$-values, corrected item-total correlation coefficients, Cronbach's alpha coefficients, percentile rank scores, and the normalized t-scores.

\section{Results and Discussion}

1) The validity of the screening inventory for Thai Muslims spouses at risk of domestic violence behaviors in Satun Province consisting of 50 question items was tested by five experts in behavioral science and psychology who considered the consistency of the question items and the characteristics to be measured or the definitions of specific terms. Then the indexes of item-objective congruence (IOC) were calculated and only items with the value from 0.5 or greater were selected because they were considered to have quality in its validity and that the experts agreed on them. The results were that the question items of the screening inventory for Thai Muslims spouses at risk of domestic violence behaviors in Satun Province had the IOC between 0.80-1.00 which indicated that the screening inventory had validity according to the criteria that had been set at 0.50 or greater (Saiyod \& Saiyod, 2000; Laeheem, 2010). This shows that the IOC of the screening inventory is at a high level when compared against the criteria for the IOC that can be used (Saiyod \& Saiyod, 2000; Laeheem, 2010) as it confirms that the screening inventory can measure according to the content, definitions, problems, objectives and characteristics to be measured. In addition, it confirms that the screening inventory has been tested and checked for correctness in terms of language and type of instrument according to the screening inventory developmental stages which include determining the scope, objectives, content, construct, definitions of variables and characteristics of the target group. Moreover, the correctness in language, type, and category of the screening inventory, and consistency with the objectives were tested by experts in the specific fields (Jamornmann, 1989; Tansawat, 2003). This screening inventory was developed with quality in its content validity that had been tested by experts, analyzed to find out its IOC and only question items with the IOC of 0.50 or greater were selected (Chaochalard, 2005; Suttayachai, 2006; Boonchu, 2006; Hirunputthichaikul, 2008).

2) The power of discrimination of the question items and the reliability of the entire screening inventory were tested through collecting data from Thai Muslim spouses in Satun Province consisting of 160 husbands and wives and then tested with t-test using the $25 \%$ technique in dividing the high and low groups. Question items with statistical significance level at .05 were selected and the coefficients of corrected item-total correlations were calculated and the question items with a coefficient of .02 or greater were selected. This is because this level of coefficient value is considered to have power of discrimination. The reliability of the entire screening inventory was also tested by measuring the internal consistency using Cronbach's alpha coefficient. The results were that the t-scores for the screening inventory for Thai Muslims spouses at risk of domestic violence behaviors in Satun Province were between 3.668-18.655, and its reliability was .936 which indicate that the screening inventory has quality in terms of discrimination power and reliability according to the criteria that were set at .20 or greater for the discrimination coefficient, and .70 or greater for the reliability of the entire inventory (Piyapimonsit, 2005; Taweerat, 1997; Saiyod \& Saiyod, 2000; Laeheem, 2010). As seen, the screening inventory from this research is a tool with quality in accordance with the principles of tool development. It also confirms that the screening inventory that has been developed can classify the target group into two groups which are a group with domestic violence risk behaviors, and a group without domestic violence risk behaviors. This corresponds with the concept that power of discrimination testing means considering its capacity in classifying subjects into two groups according to the screening inventory which are a normal group and a risk group, and in measuring the results of similar screenings (Jamornmann, 1989; Tansawat, 2003; Taweerat, 1997; Saiyod \& Saiyod, 2000). Many instruments that have been developed through research are also tested for their quality in power of discrimination by analyzing them with the t-test and selecting items with statistical significance, and by analyzing to find out coefficients and selecting items with the coefficient of 20 or greater (Chaochalard, 2005; Suttayachai, 2006; Boonchu, 2006; Hirunputthichaikul, 2008). Furthermore, the results of this research corresponds with those of various researchers in terms of discrimination power and reliability values. Pakthongchai (2006)'s screening test for risk behaviors of male teenagers' misbehaviors had power of discrimination values from 3.479 to 19.967 , and the reliability of 0.9303 while Suttayachai (2006)'s screening 
test for teenagers' quarrelling risk behaviors has power of discrimination from 5.95 to 24.93 , the coefficients from 0.23 to 0.68 , the reliability of 0.93 , and the t-scores from T21 to T90. Sensod (2006)'s screening test for anti-social risk behavior had power of discrimination values from 3.68 to 19.08 , the coefficients from 0.33 to 0.64 , the reliability of 0.94, and the t-scores from T21 to T90 while Laeheem and Sangkharat (2012)'s screening test for bullying risk behavior had the t-scores of 2.98-18.65, coefficients of .28-.82., and the reliability of .943.

3) Analysis was performed to create norms for interpretation of the screening inventory for Thai Muslims spouses at risk of domestic violence behaviors in Satun Province by collecting data from 1,920 subjects and calculating percentile rank scores to compare and find out the normalized t-scores. The scores were then interpreted in two types. Type 1 is interpretation of the 5 scales. From T-69 or higher means very high risk behaviors; T57-T68 means high risk behaviors; T45-T56 means moderate risk behaviors; T33-T44 means low risk behaviors; and T32 or lower means very low risk behaviors (Saiyod \& Saiyod, 2000). Type 2 is interpretation of two groups. From T56 or more means to have risk behaviors, and from T55 and lower means no risk behaviors (normal) (Laeheem \& Sangkharat, 2012). The results of the analysis for the screening inventory of this research revealed that the average score was 94.99; the highest score was 173, and the lowest was 49 . The percentiles were in the range 23.62 to 99.87 , and the normalized t-scores were in the range T23.62 to T80.11. Thai Muslim spouses classified to have domestic violence risk behaviors were those whose scores were from 118 or greater (T56.15 or higher). Thus, those classified to have very high domestic violence risk behaviors were those whose scores were from 169 or greater (T69.5 or higher); those classified to have high domestic violence risk behaviors were those whose scores were from 120-168 (T57.01-T68.37); those classified to have moderate domestic violence risk behaviors were those whose scores were from 74-119 (T45.26-T56.58); those classified to have low domestic violence risk behaviors were those whose scores were from 52-73 (T33.37-T44.82); and those classified to have very low domestic violence risk behaviors were those whose scores were from 51 or lower (T31.41 or lower).

From the results shown, it can be seen that the screening inventory obtained from this study is an important instrument that can be used to screen individuals who have risk behaviors according to the criteria. This instrument can, therefore, be useful for solving problems of individuals so that help can be provided for them correctly and timely. The results of the screening inventory must be kept confidential, not to make known which group of risk behaviors they belong to, and this is also to prevent them from being teased by others (Squires, Bricker, \& Potter, 1997). Screening individuals with risk behaviors is an important component of an assisting, problem solving and preventing systems that are processes with clear style and steps, methods, activities, and tools that are practical and can be conducted with close cooperation from related individuals and organizations in the community as well as those from outside (Atkins-Burnett \& Meisels, 2005; Meisels, 1988). In addition, screening is an assisting system that enables individuals to know and understand themselves, to have ways to improve and develop themselves in addition to promote and prevent problems of individuals who have risk behaviors and those who have normal behaviors (Guralnick, 2001; Squires, Bricker, \& Potter, 1997). The system needs to have quality standards, work evidence, and cooperation from all parties concerned in the community and outside, and also with clear methods and tools (Guralnick, 2001; Squires, Bricker, \& Potter, 1997; Ponsan, 2004). Thus, it can be said that screening individuals with risk behaviors is a process that prevents, promotes and systematically solves the problem for individuals who face the problem with steps, methods, tools and cooperation from all related parties using a screening process to classify the individuals into two groups or to place them into five levels.

\section{Conclusions and Recommendations}

The screening inventory for Thai Muslims spouses at risk of domestic violence behaviors in Satun Province has quality in its content validity, power of discrimination, and reliability according to the criteria. This shows that the screening inventory that has been developed is a tool that can measure according to the content, definitions of terms, problem, objectives, and characteristics to be measured. Furthermore, it is a tool that can classify the target group into two groups which are a group with risk behaviors, and a group without risk behaviors. It can also classify individuals into 5 levels which are individuals with very high risk behaviors, those with high risk behaviors, those with moderate risk behaviors, those with low risk behaviors, and those with very low risk behaviors. Which type of classification to use depends on the need required by the user of the screening inventory. Moreover, the screening inventory is a tool that can measure risk behaviors that yields similar results which corresponds with the screening tool development process. Therefore, related individuals and organizations should use it in order to concretely prevent and manage the problem of domestic violence before the problem becomes more violent and becomes a social problem, and help solve the problem in time. This screening inventory is beneficial to screening individuals with risk behaviors, and it can help screening individuals 
correctly and accurately as well as solving the problem for the right individuals before referring them to experts. In addition, organizations that are responsible for public relations should disseminate the screening inventory to other areas to be used as a primary tool that can be applied in solving the problem of domestic violence behaviors. Furthermore, it is a body of knowledge that can be used in further studies for students, academics, lecturers and the interested public.

\section{Acknowledgements}

I would like to thank the Prince of Songkla University for its financial support.

\section{References}

Archawanitkul, K., \& Im-am, W. (2003). Violence against women. Bangkok: Institute for Population and Social, Mahidol University.

Atkins-Burnett, S., \& Meisels, S. (2005). Developmental screening in early childhood: A guide (5th ed.). Washington DC: National Association for the Education of Young Children.

Berkowitz, L. (1989). The frustration-aggression hypothesis: An examination and reformulation. Psychological Bulletin, 106(1), 59-73. http://dx.doi.org/10.1037/0033-2909.106.1.59

Boonchu, D. (2006). A construction of screening inventory and prevention program for adolescents at-risk behaviors toward opposite sex relations (Unpublished master's thesis). Srinakharinwirot University, Bangkok.

Chaochalard, T. (2005). A construction of screening inventory and prevention program for adolescents' at-risk behaviors toward pornography (Unpublished master's thesis). Srinakharinwirot University, Bangkok.

Corsini, R. L. (1999). The dictionary of psychology. New York: John wiley.

Friends of Women Foundation. (2013). Situations of domestic violence in the year 2012. Bangkok: Friends of Women Foundation.

Garrett, H. E. (1965). Statistics in psychology and education. Bombey: Vakils Feffer and Simon.

Guralnick, M. (2001). A developmental systems model for early intervention. Infants \& Young Children, 14(2), 1-18. http://dx.doi.org/10.1097/00001163-200114020-00004

Hampton, R. L., Gullotta, T. P., \& Ramos, J. M. (2006). Interpersonal violence in the African American community: Evidence-based prevention and treatment practices. New York: Springer. http://dx.doi.org/10. 1007/978-0-387-29598-5

Hemmanad, H. (1990). Family violence: The case of study low invome husbands in municipal areas Muang District, Ubonratchathani Province (Unpublished master's thesis). Thammasart University, Bangkok.

Hirunputthichaikul, S. (2008). A construction of screening inventory and prevention program for adolescents at-risk behaviors toward sexual-relation (Unpublished master's thesis). Srinakharinwirot University, Bangkok.

Intarajit, I., \& Karinchai, N. (1999). Women and Children: The victim of domestic violence. Bangkok: Institute of Psychology Hot Line.

Jamornmann, U. (1989). Construction and development of measuring instruments to students' characteristic. Bangkok: Chulalongkorn University.

Kanjanakul, C. (1997). A domestic violence: A study of wife battering (Unpublished doctoral's dissertation). Srinakharinwirot University, Bangkok.

Klongpayabarn, B. (1999). Family violence: The factor associated with wives violence in Muang district, Srakaeo province (Unpublished master's thesis). Mahidol University, Bangkok.

Kungsakon, R., \& Pojam, N. (2008). Family violence. Bangkok: Srinakharinwirot University.

Laeheem, K. (2010). Data analysis for quantitative research with $R$ program, $R$ commander package. Songkhla: Prince of Songkla University.

Laeheem, K., \& Sungkharat, U. (2012). Development of screening inventory for students at risk of exposure to bullying behavior in Islamic private schools, Songkhla province. Kasetsart Journal: Social Sciences, 33(2), 175-187.

Meisels, S. (1988). Developmental screening in early childhood: The interaction of research and social policy. Annual Review of Public Health, 9(1), 527-550. http://dx.doi.org/10.1146/annurev.pu.09.050188.002523 
Office of Women's Affairs and Family. (2011). The severity of the violence situation in Thailand. Bangkok: Ministry of Social Development and Human Security.

Pakthongchai, P. (2006). A construction of screening inventory and prevention program for male adolescent's at-Risk behaviors toward sexual deviation (Unpublished master's thesis). Srinakharinwirot University, Bangkok.

Piyapimonsit, C. (2005). Using SPSS for data analysis. Songkhla: Taksin University.

Ponsan, W. (2004). A manual for at-risk student in the supporting system of secondary schools, Ratchaburi Province (Unpublished master's thesis). Srinakharinwirot University, Bangkok.

Promrak, T. (2007). Women and domestic violence: Divorce as the solution (Unpublished master's thesis). Thammasart University, Bangkok.

Puawongpaet, S. (1994). Thai Family: The problems and solutions. Journal of Public Welfare, 37(6), 20-24.

Saiyod, L., \& Saiyod, A. (2000). Testing in the affective domain. Bangkok: Suriyasarn.

Sonkin, D. J., Martin, D., \& Walker, L. A. (1985). The male batterer: A treatment approach. New York: Springer.

Squires, J., Bricker, D., \& Potter, L. (1997). Revision of a parent-completed developmental screening tool: Ages and Stages Questionnaires. Journal of Pediatric Psychology, 22(3), 313-328. http://dx.doi.org/10.1093/ jpepsy/22.3.313

Stuart, R. B. (1981). Violent behavior: Social learning approaches to prediction, management and treatment. New York: Brunner/Mazel.

Suttayachai, R. (2006). A construction of screening inventory and prevention program for adolescents' at-risk behaviors toward brawling (Unpublished master's thesis). Srinakharinwirot University, Bangkok.

Tansawat, A. (2003). A comparison of the reliability and construct validity of student stress test with different orders and scale (Unpublished master's thesis). Srinakharinwirot University, Bangkok.

Taweerat, P. (1997). Research methods for the behavioral and social sciences. Bangkok: Charoenpol.

Triemchaisri, S. (2001) Violence against women: The effects of violence and its prevention. The Journal of Nursing Science, 50(1), 8-15.

Walker, P. L. (2001). A bioarchaeological perspective on the history of violence. Annual Review of Anthropology, 30, 573-596. http://dx.doi.org/10.1146/annurev.anthro.30.1.573

\section{Copyrights}

Copyright for this article is retained by the author(s), with first publication rights granted to the journal.

This is an open-access article distributed under the terms and conditions of the Creative Commons Attribution license (http://creativecommons.org/licenses/by/3.0/). 